2. R. P. Reed, R. P. Mikese11, and A. F. C1ark, "Low-temperature tensile behavior of copper-stabilized niobium-titanium superconducting wire," in: Advanced Cryogenic. Engineering, Vol. 22, New York-London.

3. B. I. Verkin, T. A. Parkhomenko, V. V. Pustovalov, and V. I. Startsev, The LowTemperature Plasticlty of Superconducting Materials of Niobium Alloys [in Russian], Kharkov (1975) (Preprint of the Physicotechnical Institute for Low Temperatures, Academy of Sciences of the Ukrainian SSR).

4. C. C. Koch and D. S. Easton, "A review of mechanical behavior and stress effects in hard superconductors," Cryogenics, No. 7, 391-415 (1977).

5. V. P. Buryak, A. A. Galkin, N. I. Matrosov, et al., "An investigation of the properties of a superconducting conductor of $\mathrm{Nb}-\mathrm{Ti}$ alloy with ultrafine strands," in: Summaries of Papers for the 22nd A11-Union Conference on the Physics of Low Temperatures, Kishinev (1982), pp. 162-163.

6. A. Kelly and G. J. Davies, "The principles of the fibre reinforcement of metals," Met. Rev., 10, No. 37, 1-78 (1965).

7. D. A. Vigly, The Mechanical Properties of Materials at Low Temperatures [Russian translation], Mir, Moscow (1974).

8. H. Albert and J. Pfeiffer, "Festigkeit des Nb-Ti 50 supraleiters," Z. Metallkunde, 67, No. $5,356-360$ (1976).

SURFACE STRAIN-HARDENING OF THE BLADES OF GAS-TURBINE

ENGINES IN AN ULTRASONIC FIELD

V. K. Yatsenko, I. A. Stebel'kov,

UDC 621.787 .4

V. F. Pritchenko, S. B. Mikhailov,

and $\mathrm{Yu}$. P. Kichaev

The blades of gas-turbine engines (GTE) - particularly those blades made of titanium alloys - are very sensitive under variable loads to changes in the properties of the surface layer.

The effectiveness of surface-hardening of GTE blades by surface plastic deformation in an ultrasonic field [1] is determined to a considerable extent by the selection of an optimum regime.

By an optimum regime of surface strain-hardenting of GTE blades, we mean a deformation regime which will ensure adequate blade life under alternating loading and help it to withstand shock bending loads occurring in service in the event that foreign objects enter the engine.

To definttively establish an optimum strain-hardening regime, we conducted fatigue tests of alloys VT8 and ÉP718.

The 1.4-mm-thick spectmen, with a fillet having a radius of $1.2 \mathrm{~mm}$ (Fig. 1), was strainhardened for $10 \mathrm{~min}$ in an ultrasonic field by balls 2.35 and $1.3 \mathrm{~mm}$ in diameter. The strain hardening was done in a special ultrasonic device [2] using a wetting liquid.

Fatigue tests of cantilevered specimens were performed on a vÉDS-200 vibrating stand on a base of $10^{7}$ cycles until the appearance of a macrocrack (Table 1).

It can be concluded from analysis of the test results that the greatest effect is seen when alloy VT8 and steel ÉP718 are strain-hardened by 1.3-mm-diam. balls. Strain-hardening alloy VT 8 with the $2.35-\mathrm{mm}-\mathrm{diam}$. balls even reduced the endurance limit by $2 \%$.

The increase in the fatigue resistance of the specimens is due to strain-hardening of the surface layer and the formation of favorable compressive residual stresses in it (Fig. 2). The magnitude and sign of the residual stresses was determined on flat specimens measuring $1.4 \times 8 \times 60 \mathrm{~mm}$ with the aid of a PION-2 instrument.

It can be seen from Fig. 2 that strain-hardening with 2.35 -mm-diam. balls induces higherlevel compressive stresses in the flat specimens than do the 1.3-mm-diam. balls.

Zaporozhe. Translated from Problemy Prochnosti, No. 8, pp. 68-71, August, 1985. original article submitted March $14,1984$. 
TABLE 1. Results of Fatigue Tests of Specimens

\begin{tabular}{c|c|c|c|c}
\hline $\begin{array}{l}\text { No. of } \\
\text { series }\end{array}$ & Material & $\begin{array}{l}\text { Size of balls, } \\
\text { mm }\end{array}$ & $\sigma_{-1} \cdot$ MPa & $\beta^{y}$ \\
\hline & EP 718 & Initial & 320 & 100 \\
2 & EP 718 & 2.35 & 340 & 106 \\
3 & EP 718 & 1.30 & 370 & 115 \\
4 & EP 8 & Initial & 400 & 100 \\
5 & VT8 & 2,35 & 390 & 98 \\
6 & VT8 & 1,30 & 480 & 120
\end{tabular}

TABLE 2. Results of Fatigue Tests of Blades

\begin{tabular}{|c|c|c|c|c|c|c|c|c|c|c|}
\hline \multirow{2}{*}{$\begin{array}{l}\text { biancter of } \\
\text { halls, mm }\end{array}$} & \multirow{2}{*}{$\left|\begin{array}{l}\text { itrain-hard- } \\
\text { ening time, } \\
\text { inin }\end{array}\right|$} & \multirow[b]{2}{*}{$\begin{array}{l}\bar{n}-1 . \\
\text { MPa }\end{array}$} & \multirow[b]{2}{*}{$\begin{array}{l}S_{\sigma_{-1}} \\
M_{P_{1}}\end{array}$} & \multirow{2}{*}{ 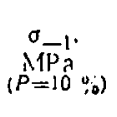 } & \multirow[b]{2}{*}{$v_{\sigma_{-1}}$} & \multirow[b]{2}{*}{$\beta y$} & \multicolumn{4}{|c|}{ Site of blade fractire } \\
\hline & & & & & & & $\begin{array}{l}\text { inlet } \\
\text { edge }\end{array}$ & $\begin{array}{l}\text { Outlet } \\
\text { edge }\end{array}$ & $\begin{array}{l}\text { back } \\
\text { edge }\end{array}$ & Face \\
\hline $\begin{array}{l}1.3 \\
.2 .35 \\
2,3 \\
2.35\end{array}$ & $\begin{array}{r}5 \\
5 \\
111 \\
10\end{array}$ & $\begin{array}{l}69,5 \\
63.7 \\
63,6 \\
62,8\end{array}$ & $\begin{array}{l}3.0 \\
+.5 \\
4.1 \\
5.5\end{array}$ & $\begin{array}{l}64.9 \\
58.0 \\
58.4 \\
54.4\end{array}$ & $\begin{array}{l}0.051 \\
0.070 \\
0.070 \\
0.087\end{array}$ & $\begin{array}{l}129 \\
116 \\
117 \\
109\end{array}$ & $\begin{array}{l}0 \\
1 \\
2 \\
1\end{array}$ & $\begin{array}{l}5 \\
7 \\
7 \\
9\end{array}$ & $\begin{array}{l}5 \\
2 \\
1 \\
0\end{array}$ & $\begin{array}{l}0 \\
0 \\
0 \\
0\end{array}$ \\
\hline Vihronolisterl & - & 50.0 & 4,9 & 50.1 & 0,081 & 100 & 2 & 0 & 6 & 2 \\
\hline
\end{tabular}

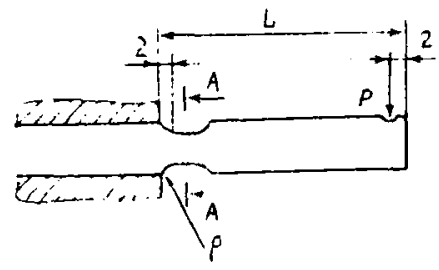

$\underline{4-1}$

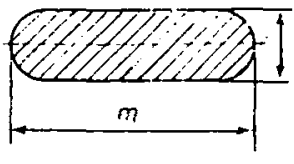

Fig. 1. Diagram of specimen for fatigue tests.
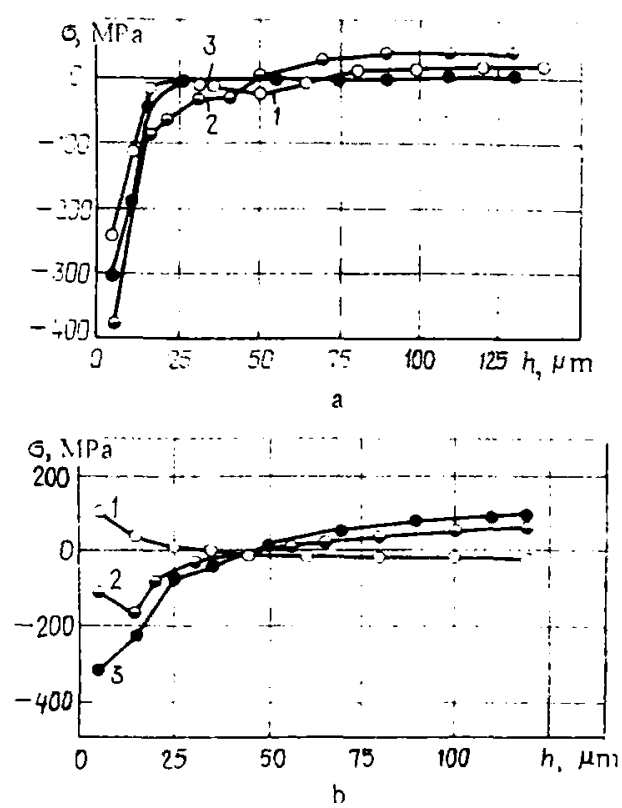

Fig. 2. Curves of axial residual stresses measured on specimens of alloy VT8 (a) and steel EP718 (b) after grinding (1) and strain-hardening in an ultrasonic field with balls 1.3 (2) and 2.35 (3) $\mathrm{mm}$ in diameter.

Measurements of surface roughness showed that the original and strain-hardened steel ÉP718 specimens had $\mathrm{Ra}=0.25 \mu \mathrm{m}$, while the alloy VT 8 specimens had $\mathrm{Ra}=0.6 \mu \mathrm{m}$. Thus, 
TABLE 3. Results of Tests of Blades with a Weight $G=2470 \mathrm{~g}$

\begin{tabular}{|c|c|c|c|c|c|}
\hline Type of blade treatment & $\varphi_{\min }^{0} d: g$ & $\Phi_{\max }^{0} \cdot \operatorname{deg}$ & $\overline{\varphi^{\circ}} \cdot \operatorname{deg}$ & $s_{\varphi^{p}}$ & $\boldsymbol{v}_{\boldsymbol{\varphi}^{\bullet}}$ \\
\hline $\begin{array}{l}\text { Vibropolishing } \\
\text { Uitrasonic strain hardening }(\tau=5 \mathrm{~min}, \varnothing 1,3 \mathrm{~mm}) \\
\text { Same }(\tau=10 \mathrm{~min}, \varnothing 1,3 \mathrm{~mm}) \\
\text { Same }(\tau=5 \mathrm{~min}, \varnothing 2.35 \mathrm{~mm})\end{array}$ & $\begin{array}{l}19.1 \\
20.6 \\
19.8 \\
20.7\end{array}$ & $\begin{array}{l}23,4 \\
23,1 \\
24.7 \\
25.6\end{array}$ & $\begin{array}{l}21.2 \\
21.9 \\
22,2 \\
23,1\end{array}$ & $\begin{array}{l}1.64 \\
0.93 \\
1.85 \\
1.85\end{array}$ & $\begin{array}{l}0,08 \\
0,04 \\
0,08 \\
0,08\end{array}$ \\
\hline
\end{tabular}

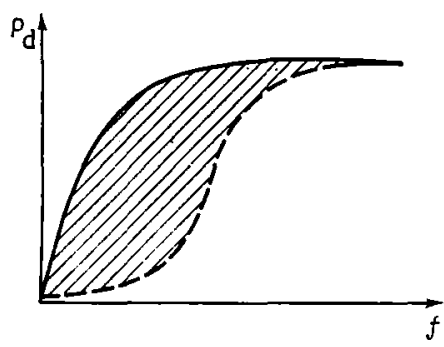

Fig. 3. Dependence of deflection of rod end $f$ on dynamic force $P_{d}$. (The solid line shows results obtained without allowance for residual stresses, while the dashed line shows results obtained with allowance for same.)

strain-hardening the specimens in an ultrasonic field with balls 1.3 and $2.35 \mathrm{~mm}$ in diameter did not lead to a reduction in surface-roughness parameters.

It should be noted that a more favorable surface microrelief is formed after the above strain-hardening than after manual polishing and vibropolishing.

Strain-hardening of alloy VT8 with the $1.3 \mathrm{~mm}$ balls produced no discernible changes in surface microhardness, while use of the $2.35 \mathrm{~mm}$ balls increased microhardness by $4 \%$.

A sharp increase in the degree of strain-hardening was seen on the steel ÉP718 specimens; strain-hardening with both the $1.3 \mathrm{~mm}$ balls and the $2.35 \mathrm{~mm}$ balls leads to an increase of 20 and $19 \%$, respectively, in the degree of strain-hardening.

To confirm the results obtained on the above specimens, we conducted fatigue tests of blades of alloy VT8 strain-hardened with 1.3 and $2.35 \mathrm{~mm}$ balls for 5 and $10 \mathrm{~min}$.

It should be noted that the thin blade edges are placed under adverse conditions when the strain-hardening is done with larger balls. This may lead to the formation of fatigue cracks in tests at the edges. After we subjected the blades to fatigue tests, we etched them in hydrofluoric acid to determine sites of crack nucleation. The results of blade tests shown in Table 2 confirm that the smaller, 1.3-mm-diam. balls should be used for strain-hardening in an ultrasonic field. Use of the 2.35-mm-diam. balls and an increase in strain-hardening time from five to $10 \mathrm{~min}$ weakens the thin edges of the blades relative to the back, which is more heavily loaded in service. At the same time, strain-hardening of the blades for $5 \mathrm{~min}$ with the $1.3 \mathrm{~mm}$ balls ensures edges and back of equal strength.

Strain-hardening can be made even more effective by increasing treatment time while using special shields to protect the edges from excessive straining.

It should be noted that ultrasonic strain-hardening not only increases the fatigue strength of alloy VT8, but it also stabilizes the physicomechanical properties of the surface layer and neutralizes possible surface defects (lines). This is confirmed by the $60 \%$ decrease in the spread of the endurance limit compared to vibropolished blades.

Analysis of blade service data shows that when foreign objects enter the air channel of the engine they collide with the compressor blades. Thus, in using surface strain-hardening for blades of alloy VT8, it is necessary to evaluate the effect of this treatment on the resistance to impact bending loads.

Since the maximum tensile stresses occur in the blade surface layers during impact bending, and the residual stresses created by finishing are also in these layers, the effect of the latter must be considered in any elastoplastic calculation. 
We will examine a cantilevered rod loaded on its end by a dynamic impulsive force. Ignoring the effect of the transverse force creating the maximum shear stresses in the center of the cross section and the inertial forces of the rod, it can be assumed that the rod (blade) undergoes pure bending during deformation by the load. We will simplify the calculation by taking a symmetrical rod cross section relative to the bending $p l$ ane and a linear stress state. The change in the resistance to impact bending due to the increase in the hardness of the surface layer is not considered.

We direct the $X$ and $Y$ axes perpendicular to the $Z$ axis of the rod so that the bending plane will be YOZ.

The stresses created during impact bending should be as follows in accordance with the adopted hypothesis of plane sections for an ideally plastic material:

$$
\sigma=\left\{\begin{array}{l}
\left.\theta\left(Y-Y_{0}\right) E+\sigma_{0}, \sigma \leqslant \sigma_{\mathrm{t}} \text { (region of section } \bar{F}\right) ; \\
\left.\sigma_{\mathrm{t}} \operatorname{sign}\left(\sigma_{\mathrm{y}}\right), \sigma_{\mathrm{y}}>\sigma_{\mathrm{t}} \text { (region of section } F^{*}\right),
\end{array}\right.
$$

where $F$ is the cross sectional area of the rod, $F=\bar{F}+F^{*} ; \bar{F}$ is the region of elastic stresses; $F^{*}$ is the region of elastoplastic strains; $\sigma_{y}$ is the theoretical elastic stress in the region $F^{*} ; \sigma_{y}=\theta\left(Y-Y_{0}\right)+\sigma_{0} ; \theta$ is the relative angle of rotation of a plane section under the influence of the bending moment $\mathrm{M} ; \mathrm{Y}$ is the running coordinate; $\mathrm{Y}_{0}$ is the position of the origin of the coordinates (the neutral line); $E$ is the elastic modulus of the material; $\sigma_{d}$ is the yield point of the material; $\sigma_{0}$ is the initial stress, $\sigma_{0}=f(Y)$.

The sign function is determined by the relation

$$
\operatorname{sign}\left(\sigma_{\mathrm{y}}\right)=\left\{\begin{array}{rr}
1, & \sigma_{\mathrm{y}}>0 \\
-1, & \sigma_{\mathrm{y}}<0
\end{array}\right.
$$

From the equilibrium condition

$$
\int_{F} \sigma d F=0 \text { and } \int_{F} \sigma\left(Y-Y_{0}\right) d F=M
$$

we obtain the position of the coordinate origin

$$
Y_{0} \int_{\bar{F}} Y d F / F+\int_{F^{*}} \sigma_{\mathrm{t}} \operatorname{sign}\left(\sigma_{\mathrm{y}}\right) d F / \theta E \bar{F}
$$

and the relative angle of rotation

$$
\theta^{\mathrm{pl}}=\left(M-\int_{F^{\bullet}} \operatorname{sign}\left(\sigma_{\mathrm{y}}\right)\left(Y-Y_{0}\right) d F\right)^{\prime} \int_{\bar{F}} E\left(Y-Y_{0}\right)^{2} d F
$$

considering that the integral $\int_{F_{*}} \sigma_{\mathrm{t}} \operatorname{sign}\left(\sigma_{y}\right)\left(Y-Y_{0}\right) d F>0$.

Since the plastic region $F^{*}$ begins to develop in the compressed surface layers $\left(\sigma_{y}>0\right)$ and

$$
\theta^{\mathrm{y}}=M / E \int_{\dot{\bar{F}}}\left(Y-Y_{0}\right)^{2} d F=\frac{M}{E I_{x}},
$$

it can be shown that

$$
\theta^{\mathrm{pl}}>\theta^{\mathrm{y}} \text {. }
$$

Figure 3 shows the dependence of the deflection of the rod end $f$ on the dynamic force $P_{d}$. The area under the curve $P_{d}(f)$ in $F i g, 3$ is also the potential strain energy of the rod. Thus, in impact tests, the deflection and angle of rotation of the rod end will be somewhat greater for a rod with residual stresses than for one without such stresses. The increase in the angle of rotation should be proportional to the potential strain energy of the rod (the hatched region in Fig. 3).

Blades were subjected to repeated impact in tests conducted on a special unit. The blades were installed in a locking device which was in turn secured in the support of the unit with a constant force. The impact was delivered by changeable weights secured to a pendulum. The impact was delivered to the face of the blade $6 \mathrm{~mm}$ from its footing. PreIiminary tests established that the most dangerous site for Impact by a foreign object is the zone near the blade footing. The weights had the shape of the blade face, which made 
it possible to deliver the impact in the middle part of the blade and avoid damaging the edges. After each impact we recorded the cumulative plastic strain and indirectly measured the angle of bending of the blade to within $\pm 0.25^{\circ}$. The tests were stopped when the weights wedged in the blade or when the blade broke.

We tested vibropolished blades of the first stage of a high-pressure compressor and blades strain-hardened by balls $1.3 \mathrm{~mm}$ in diameter for $5 \mathrm{~min}$ and $10 \mathrm{~min}$ and by balls $2.35 \mathrm{~mm}$ in diameter for $5 \mathrm{~min}$.

The effect of the strain-hardening regime on resistance to impulsive loads was determined in the tests with weights of weight $G=2470$ and $3530 \mathrm{~g}$. The impact strength of the blades was evaulated and compared according to the angle of bend $\varphi^{\circ}$ obtained after the first impact. Eight specimens were tested in each lot. With allowance for the scatter of the test results, we performed a statistical analysis and determined the $99 \%$ confidence intervals for an angle of bend $\varphi^{\circ}[3]$ :

$$
\bar{\varphi}^{0}-t_{q, n-1} \frac{S_{\varphi^{0}}}{\sqrt{n-1}}<\varphi^{0}>\bar{\varphi}^{0}+t_{q, n-1} \frac{S_{\varphi^{0}}}{\sqrt{n-1}}
$$

where $t_{q, n-1}$ is the Student criterion (see Table $V$ in [3]); $S_{\Phi^{\circ}}$ is the standard deviation of the bend angle $\varphi^{\circ} ; \mathrm{n}$ is the number of blades in a lot, $\mathrm{n}=8$.

The results of the investigation are shown in $\mathrm{Table} 3$. It can be seen that there is a slight increase in the bend angle of the strain-hardened blades, which confirms the earlier conclusions. It is typical that the least scatter of plastic strain is also seen for the blades strain-hardened by 1.3-mm-diam. balls for $5 \mathrm{~min}$.

Consequently, the completed tests convincingly show that the time of strain-hardening of small blades of alloy VT8 by $1.3-\mathrm{mm}$-diam. balls should be no greater than 5 min if the edges are not protected by shields. Such strain-hardening significantly increases the endurance limits of blades with almost no reduction in their resistance to impact loads.

\section{LITERATURE CITED}

1. I. A. Stebe1'kov, "Method of surface strain-hardening," Inventor's Certificate No. 456704, Byul1. Izobret., No. 2 (1975).

2. I. A. Stebel'kov, "Ultrasonic unit for strain-hardening parts," Inventor's Certificate No. 608564, Byul1. Izobret., No. 20 (1978).

3. N. V. Smirnov and I. V. Dunin-Barkovskii, Course in the Theory of Probability and Mathematical Statistics for Engineering Applications [in Russian], Nauka, Moscow (1969). 